\title{
AQUISIÇÃO DE VISÃO ESPACIAL PELO ESTUDO TEÓRICO-PRÁTICO DE ESTRUTURAS TECTÔNICAS EM DIFERENTES ESCALAS DE OBSERVAÇÃO
}

\author{
ALEXIS ROSA NUMMER* \& CELSO DAL RÉ CARNEIRO**
}

\begin{abstract}
THE SPATIAL VISION ACQUISITON BY MEANS OF THE THEORETICAL-PRACTICAL STUDY OF TECTONIC STRUCTURES IN DIFFERENT SCALES OF OBSERVATION The teaching-learning of geologic processes often faces the outstanding problem, mainly for Structural Geology, of comprehension of space. The difficulties become clearer when major regional structures are studied in the field as opposed to maps and representations or lab-models studied in classroom. The described series of didactic fieldtrips in a Structural Geology discipline of the Geology undergraduate course at the Rio de Janeiro Federal Rural University follow motivating and investigative guidelines; they have considered the previous knowledge of the students. When asked to recognize large-scale folds in a Precambrian area the students performed the required tasks with both good cognitive results and excellent spatial learning. A number of techniques was adopted allowing an identification of: (a) relationship among students; (b) personal aims and perspectives; (c) previous geological knowledge; (d) understanding of spacial concepts as a means to improve the discipline; (e) professional expectations; ( $\mathrm{f}$ ) evaluation of subsidiary geometry concepts helpful for understanding natural structures. The teacher should take into account the characteristics of the students. The doubts should not be immediately answered by the teacher to stimulate further developments. Personal yield is analyzed as a balance between specific abilities and deficiencies. The approach of thinking and practicizing science was not exhausted but it is a fundamental research tool on links between natural processes and features. The first non-oriented fieldtrip resulted in a lot of questions and low productivity; the second excursion (when students have already learned basic concepts of Structural Geology) was mainly for training basic tools but became investigative at the end. Students also tried to make a map plotting of the outcrops on different scales and associated the observed features to the local relief. The adoption of an inverse order (theory was presented after practical work) enhanced the participation of both students and teacher. The second fieldwork allowed a theoretical discussion on the postulates of scientific methodology. The large-scale fold and related structures were unknown by the teacher who selected the outcrops but he identified some diagnostic characteristics of a major regional fold just before the students. Nevertheless, this conceptual jump apported new information which is useful for a future inductive activity.
\end{abstract}

Keywords: geology teaching, spatial vision, Structural geology

RESUMO O problema da aquisição de visão espacial afeta o ensino-aprendizagem de processos geológicos, notadamente na abordagem de Geologia Estrutural. As dificuldades aumentam no estudo de estruturas de grande porte no campo, em lugar de representações em sala-de-aula ou laboratório. Esta nota discute experiência pedagógica conduzida no curso de graduação em Geologia da Universidade Federal Rural do Rio de Janeiro, envolvendo atividades de campo de caráter motivador e indutivo. Aproveitaram-se os conhecimentos prévios dos alunos, de modo a levá-los a redescobrir dobras de grande porte em área de rochas pré-cambrianas, com excelente aproveitamento cognitivo, de visualização espacial e de motivação. O método desenvolvido possibilitou a cada estudante perceber, com relativa facilidade, feições de grande porte existentes. Recuperou-se o entusiasmo de alunos desmotivados, graças ao entrelaçamento teoria-prática. Para incorporar o cotidiano do aluno, foram realizados workshops, discussões, questionários individuais e formação de grupos de trabalho, detectando-se elementos como: (a) relacionamento entre alunos; (b) objetivos e perspectivas no curso; (c) pretensão dentro e fora da futura atividade profissional; (d) conhecimentos prévios de geologia e entendimento sobre a contribuição dessas noções na disciplina; (e) avaliação de conceitos de geometria que auxiliassem o desempenho e a visão espacial de formas da natureza. O professor adotou postura aberta e flexível, analisando a produção e identificando características individuais, problemas, habilidades e deficiências específicas dos alunos. Indagações ficariam sem respostas imediatas, como incentivo à discussão e para estimular que fossem desenvolvidas pêlos alunos, segundo o mecanismo no qual o aluno "pensa e faz ciência", procurando definir relações e associações entre processos e feições naturais. Em cada uma das situações evitou-se esgotar os assuntos. $\mathrm{O}$ trabalho de campo inicial foi motivador, sem participação dirigida do professor; a segunda excursão teve caráter eminentemente treinador no início e indutivo no final, pois os alunos já dispunham de conceitos básicos sobre estruturas em corpos rochosos. Embora tenha sido invertida a ordem usual, fazendo-se a prática antes da teoria - das relações entre diferentes escalas de observação - a atividade atingiu os níveis cognitivos de análise, síntese e avaliação, com participação equilibrada de alunos e professor. A atividade foi indutiva pois o docente que havia selecionado os melhores afloramentos do perfil não sabia da existência de uma megadobra; entretanto, ele identificou algumas características diagnosticas dessa dobra regional antes dos estudantes. Pode-se afirmar que as dificuldades desse salto conceituai propiciaram a realização de uma atividade investigativa.

Palavras chaves: ensino da geologia, visão espacial, geologia estrutural

INTRODUÇÃO O ensino-aprendizagem de Geologia Estrutural é permanentemente desafiado pelo problema da aquisição de visão espacial. A visualização espacial é básica para abordagem dos processos geológicos, notadamente nos campos da Geologia Estrutural, Desenho Geológico e Geotectônica. Quando, em lugar da sala de aula ou do laboratório, os estudantes procuram trabalhar com estruturas de grande porte diretamente no campo, tais dificuldades assumem proporcões ainda mais nítidas.

O campo oferece uma "situação insubstituível de aprendizagem de Geologia" (Anguita 1992) cujas peculiaridades exigem análise aprofundada. O presente texto busca contribuir para o estudo de técnicas utilizadas por docentes de Ensino Superior, com ênfase nas referidas disciplinas. Sugerem-se algumas ferramentas de trabalho que podem melhorar os resultados do processo de ensino-aprendizagem em Geologia Estrutural, a partir de experiência conduzida pelo primeiro autor em 1994, no Curso de Especialização em Ensino de Geociências (CEEG), oferecido pelo atual Departamento de Geociências Aplicadas ao Ensino do Instituto de Geociências da Universidade Estadual de Campinas (DGAE-IG-Unicamp). São descritas e avaliadas atividades didáticas concebidas para facilitar o desenvolvimento de visão espacial de alunos de Geologia Estrutural do Curso de Geologia da Universidade Federal Rural do Rio de Janeiro. A área escolhida para realização de trabalhos de campo situa-se no sudeste brasileiro (Fig. 1), a leste dos limites entre os estados de São Paulo e Rio de Janeiro e em domínio de rochas cristalinas que afloram aproximadamente a sudeste da Bacia tafrogênica de Resende.
O CURSO DE ESPECIALIZAÇÃO EM ENSINO DE GEOCIÊNCIAS No ensino brasileiro, a maioria dos docentes de disciplinas geológicas das Licenciaturas em Ciências, Geografia, Biologia e Química não é formada por geólogos. Essa pode ser uma causa, ao lado de outras já conhecidas, de deficiências conceituais e metodológicas na aplicação de princípios de Geologia. Exclusivamente dedicado a professores em exercício, o CEEG da Unicamp constitui instrumento de conscientização pedagógica, procurando criar condições teóricopráticas para análise de princípios e modelos pedagógicos gerais, natureza do conhecimento geológico e metodologias específicas para efetiva aprendizagem de Geociências. Busca-se, sobretudo, situar tais parâmetros sob as condições de contorno em que se desenvolve o ensino superior no país, representadas pela política educacional.

Tais correlações visam capacitá-los instrumental e criticamente a realizar renovações nos planos programáticos e metodológicos das disciplinas que ministram. A experimentação prática - denominada Trabalho-Piloto (TP) - procura gerar mudanças que levem em conta os múltiplos aspectos da realidade na qual cada professor atua. $\mathrm{O}$ curso foi frequentado por grupo de professores de terceiro grau (nível superior), de instituiçỗes públicas e privadas, escolas técnico-profissionalizantes e outros cursos de formação de professores. A diversidade de experiências individuais enriqueceu as discussões, envolvendo a problemática do ensino ao longo da história brasileira e preocupações quanto a aspectos fundamentais para o desenvolvimento educacional do aluno: postura frente ao cotidiano, independentemente

* Departamento de Geociências, Universidade Federal Rural do Rio de Janeiro (UFRRJ). Km 47, antiga estrada Rio-São Paulo, Seropédica-Itaguaí, 28851 -970, Rio de Janeiro, RJ. E-mail:nummer@copmuland.com.br

** Departamento de Geociências Aplicadas ao Ensino, Instituto de Geociências, Universidade Estadual de Campinas (UNICAMP). Caixa Postal 6152,13083-970, Fax (O xx 91)289 1562, Campinas SP.E-mail: cedrec@ige.unicamp.br. 
Mapa de situação, Brasil

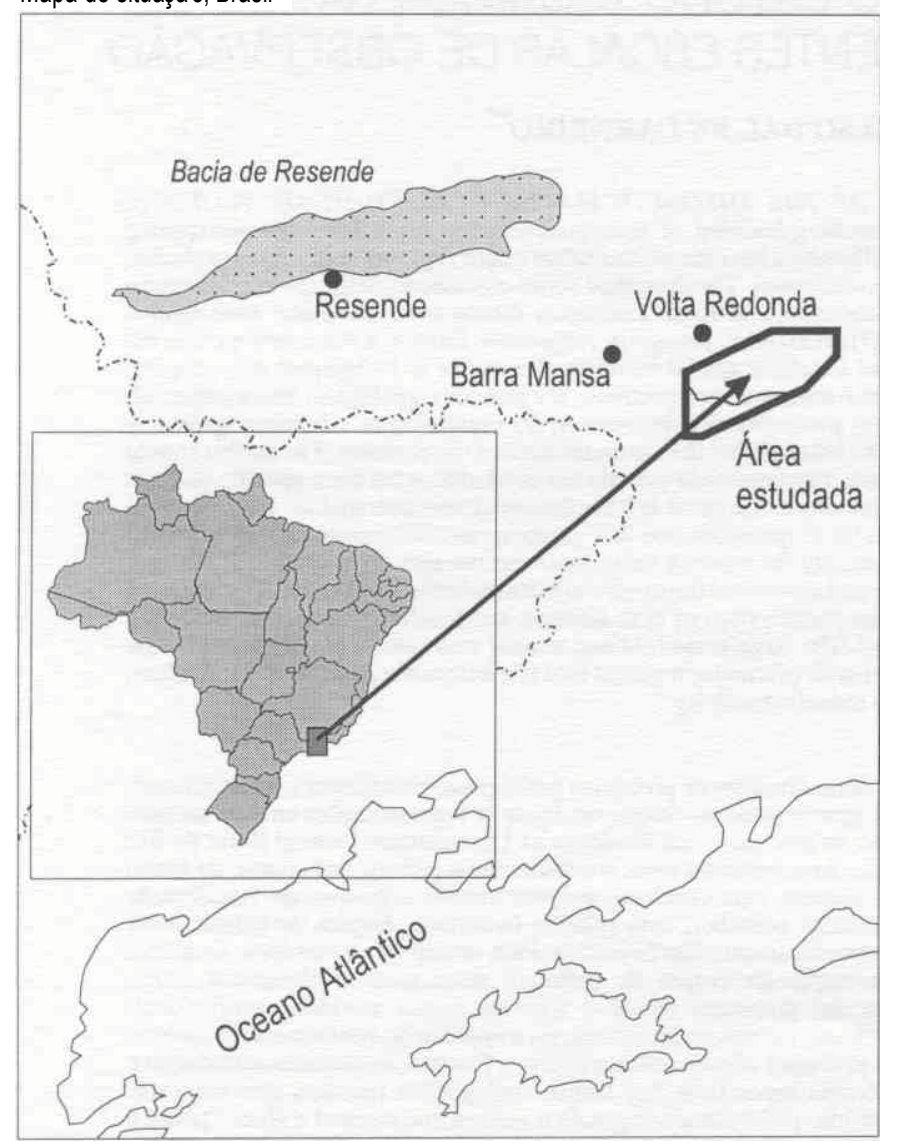

Figura l - Posição da área na região sudeste do Brasil

do grau de escolaridade do aluno; conhecimento do contexto social deste e o problema do aproveitamento de seus conhecimentos prévios. No curso de 1994 emergiram vários aspectos essenciais, a seguir resumidos. Constatou-se uma necessidade básica do ensino público superior, vinculada ao baixo aporte de recursos para pesquisa. $\mathrm{O}$ ensino ministrado em escolas particulares exibe problemas no aspecto financeiro (extrema voracidade por recursos), excesso de alunos por turma e falta de interesse pela qualidade de ensino. Em contraponto, o ensino público apresenta grande taxa de evasão de alunos, sucateamento do património, falta de verbas, acentuada "cobrança" de produtividade em pesquisa e alta carga didática.

O PAPEL DA HISTÓRIA DAS CIÊNCIAS No contexto do curso, houve acentuado interesse pelo estudo de história geral das Ciências e aspectos específicos da história das Ciências no Brasil, com ênfase para as Geociências. Por meio de análise de textos, avaliaram-se atividades didáticas envolvendo abordagens históricas do conhecimento, pelo lado das grandes controvérsias científicas ou das tradições científicas das nações. A história da Geologia e das Ciências pode criar um "pano-de-fundo" para desenvolvimento dos conceitos, aspecto que facilita o entendimento das Geociências. Resultou, no grupo, grande valorização do uso dessa ferramenta de ensino-aprendizagem.

Exibições de vídeos didáticos geraram discussões quanto a determinados fatos científicos e seus vínculos com a corrente de pensamento dominante na época da produção. Detalhes históricos de elaboração permitiram analisar a origem ou procedência do filme, concluindo-se que filmes didáticos são excelentes recursos audiovisuais, que aumentam o nível de discussão e o interesse por assuntos polêmicos.

A QUESTÃO PEDAGÓGICA A "necessidade do diálogo como estratégia de ensino" (Freire, apud Gadotti 1988), deve ser um elemento básico de formulação metodológica, enquanto esta última deve ser considerada uma "interpretação e compreensão da realidade apoiada na prática específica" (Fisher 1976).

$\mathrm{O}$ aspecto puramente repetitivo do ensino reproduz a divisão social do trabalho entre o pólo mental e outro manual. O currículo escolar manifesta o próprio código social dominante, no qual "infelizmente a história da educação tradicional, demasiadamente centralizada na forma idealista na evolução de ideias e muito pouco nos dispositivos materiais (como a sala de aula e os métodos pedagógicos reais) pouco têm contribuído para aumentar nossa compreensão desses processos histórico-genéticos" (Silva 1992).

A TEORIA, NA PRÁTICA Moreira (1992) tece reflexões sobre a produção do conhecimento nas salas de aula: o currículo como fato que condiciona a educação como transmissora cultural, por meio de seus professores, em disciplinas adequadamente dispostas. O currículo como prática rejeita a hierarquia entre a teoria e a prática, na medida em que é exercido por meio de seleção e avaliação arbitrárias dos professores e alunos. Por outro lado, o comprometimento do homem com a natureza e sociedade sacramenta a união entre a teoria e a prática para o efetivo desenvolvimento do ensino; o autor destaca ainda a existência do "currículo oculto", um representante invisível de mecanismos de dominação comuns nos sistemas políticos e sociais.

O conhecimento é elemento inseparável do processo histórico, das pessoas e de seu uso. Constitui, antes, um instrumento dos homens para enfrentar os problemas de formação individual na nova ordem social, na qual a escola democrática é necessidade imperativa. Na visão construti vista do ensino, sujeito e meio são importantes, na medida em que se considera o conhecimento como um processo inacabado (Becker 1993).

Ao planejamento sistêmico, caracterizado pela formulação racional e científica, pode-se contrapor o planejamento participativo, idealmente concebido (Sant' Anna et al. 1988), que deve contar com a colaboracão efetiva das pessoas envolvidas no processo. Os dois tipos de planejamento requerem transformações para mudar ou manter o sistema vigente. Dependem, exclusivamente, da escala de abordagem do planejamento e dos objetivos específicos propostos para o ensino. O planejamento sistémico define muitos parâmetros para programar atividades, sempre de modo racional e, de acordo com as avaliações e necessidades (diagnósticos) do meio, busca considerar as reais limitações e possibilidades de sucesso. O planejamento de ensino excessivamente sistematizado pode não ser o melhor caminho "pois, eventualmente, vários fatores negativos podem imperar ao longo do processo de execução" (Sant' Anna et al. 1988). Conquanto certas transformações gerais em Educacão sejam difíceis de promover, inúmeras mudanças podem ser realizadas no planejamento de pequenas unidades de ensino.

PRÁTICAS DE CAMPO O objetivo principal de muitos estudantes que ingressam no curso de Geologia é serem geólogos de campo. As atividades de campo são assistidas com o máximo interesse, pois ajudam a alcançar o objetivo inicial. Nessas situações, porém, a relação de ensino-aprendizagem é demasiadamente complexa; com frequência, o aluno questiona o docente, quando encontra dificuldade para entender uma linha de raciocínio qualquer.

Um breve esboço de vantagens e desvantagens dos papéis das atividades de campo (Compiani \& Carneiro 1993), detectadas a partir de leituras e debates em pequeno grupo, sugere algumas questões que devam ser analisadas.

A atividade de campo ilustrativa é centrada no professor; requer conceituação prévia de aspectos fundamentais da teoria e possui caráter informativo. Trata a ciência como produto acabado e requer ampla memorização pelo aluno. $\mathrm{Na}$ atividade indutiva ocorre uma limitação e não-criação por parte do aluno. A atividade indutiva difere da ilustrativa pelo caráter formativo mais acentuado. Para certos alunos dispersos, este tipo de excursão é ideal, auxiliando em sua formação, pois a indução estimula a observação de pormenores das atividades de campo, como orientação, sucessão estratigráfica $X$ posição topográfica, confecção de croquis etc.

Excursões motivadoras podem ser inseridas como objetivo inicial, em qualquer curso e, dependendo do público-alvo, constituem abordagem fundamental. Possuem caráter essencialmente formativo. A atividade treinadora, quando aplicada a alunos em qualquer estágio de escolarização, origina um elo efetivo entre os conhecimentos teóricos adquiridos ao longo do curso e sua aplicação prática. No mercado de trabalho, pode traduzir os anseios atuais de empresas frente ao perfil dos profissionais contratados. Possui caráter tanto formativo, quanto informativo. O último tipo de excursão abordada por Compiani \& Carneiro (1993) é a investigativa, que seria o papel ideal das atividades de campo. Deve ser enquadrada segundo objetivos teóricos-práticos bem definidos, para a realização de trabalhos mais completos e complexos no campo da Geologia.

Além de ser atividade frequentemente mais complexa, tal relação ensino-aprendizagem oferece resultados indiscutivelmente mais efi- 
cazes para o futuro profissional de Geologia. Possui caráter eminentemente formativo.

AVALIAÇÃO O último aspecto a ser abordado refere-se à análise e avaliação crítica das atividades didáticas, em função dos objetivos propostos no programa inicial. Quando ocorre uma estruturação e apresentação prévia dos objetivos a serem alcançados, o processo de ensino-aprendizagem torna-se mais eficaz.

A análise criteriosa do conteúdo da disciplina é fundamental para se melhorar a qualidade da avaliação formal. Para avaliarmos alguém, há outros fatores a considerar no processo de aprendizagem, com destaque para a análise da evolução e crescimento, nos alunos, de valores teóricos, práticos e humanos. Ao mesmo tempo, deve-se estudar e fomentar sua expressão criadora, lembrando que a avaliação é um processo contínuo. O professor deve procurar minimizar os efeitos negativos da avaliação formal imposta pela instituição e, finalmente, aprofundar-se na rigorosa definição de pré-requisitos para cada disciplina.

APLICAÇ̃̃O DO TRABALHO-PILOTO (TP) O ensino de disciplinas que necessitam de visão espacial aprimorada afeta diretamente a qualidade dos cursos de Geologia, pois abrange conceitos e habilidades cuja aquisição é fundamental para a prática ulterior do futuro geólogo. Duas questões refletem-se no desempenho dos estudantes: as escalas de observação e as dificuldades que estes normalmente encontram para visualizar e interpretar traços nas rochas. Desse modo, escolheu-se uma situação prática - no campo e em sala-de-aula - na disciplina de Geologia Estrutural, para avaliar em que medida o emprego de novas técnicas e abordagens didáticas poderia estimular, desafiar e até promover conquistas no processo pedagogico.

Resumidamente, as principais características da turma na qual foi aplicado o TP são: baixa faixa etária e de renda, insatisfação quanto ao curso, futuro profissional incerto e desmotivação geral.

Diante dessas características, o trabalho foi inicialmente realizado procurando-se incorporar nas atividades didáticas o cotidiano do aluno, realizando-se workshops, discussões, questionários individuais e formação de grupos de trabalho. Esses trabalhos visavam detectar os seguintes elementos:

a)relacionamento entre alunos;

b)caracterização dos objetivos e perspectivas durante o curso;

c) pretensão dentro e fora da futura atividade profissional;

d) conhecimentos de geologia previamente adquiridos e de que

forma os alunos entendiam que tais conhecimentos poderiam contribuir para a disciplina;

e)conceitos de geometria que poderiam auxiliar diretamente o desempenho e a visão espacial de formas da natureza.

A postura do professor nas atividades programadas deveria ser aberta e flexível, para identificar os problemas e características individuais dos alunos. A produção de cada aluno deveria ser analisada relacionando-se suas habilidades e deficiências específicas, exatamente pelo fato de que cada aluno deveria ser encarado como indivíduo. As indagações seriam desenvolvidas pêlos alunos com o consequente incentivo à discussão, mas sem respostas imediatas por parte do professor. Seria fundamental montar um mecanismo para que o aluno pensasse e fizesse ciência sistematicamente, ou seja, procurando definir melhor as relações e associações entre processos e feições naturais, não como conhecimento acabado, mas como algo a ser desenvolvido, sem tentar esgotar os assuntos.

ORGANIZAÇÃO DO CONTEÚDO Na introdução ao tema, leituras opcionais de História da Geologia permitiram ilustrar fases da evolução do Conhecimento Geológico. Para concentrar o trabalho em Geociências, procurou-se melhorar o entendimento da relação entre esta última e as demais ciências. Em suma, buscou-se obter padrões críticos mais adequados para situar a importância dos trabalhos de campo realizados por geólogos.

Um vídeo educacional buscou encorajar os alunos a pesquisar, aprender e estudar a História da Terra. O filme Grand Canyon (Britannica 1985), rico em analogias espaciais, enfatiza que, para explicar o presente, devemos compreender fatos ocorridos no passado. $\mathrm{O}$ Grand Canyon encerra o mais abrangente e diversificado registro do tempo geológico da Terra conhecido em um único sítio. A análise de analogias entre a sucessão vertical dos estratos com o relógio do tempo geológico possibilita uma visão crítica e facilita o entendimento do pensamento geológico atual.

Após a apresentação do filme foi programado um painel em grande grupo que obteve resultado satisfatório, pelo fato de os alunos jamais terem assistido ao filme e não possuírem conhecimento prévio dos assuntos ali abordados. A discussão procurou relacionar os elementos históricos com os conceitos de evolução espacial, gerando dúvidas e questões quanto ao tema "tracos geológicos nas rochas". A interdependência professor-aluno equilibrou-se, descentralizada tanto do professor como do aluno; os questionamentos foram estimulados pelo professor para que se atingisse o resultado esperado; não foram definidas previamente as conclusões que deveriam ser obtidas; foi admitido o raciocínio lógico do aluno sem eventual censura diante de possíveis imperfeições.

CAMPO Partindo-se do trabalho pedagógico programado, a disciplina contou com duas excursões experimentais:

a)a primeira foi centrada exclusivamente no aluno, sem participação orientadora do professor (motivadora). Resultou em vários questionamentos dos próprios alunos e a produtividade foi sofrível. Para este tipo de excursão, a elaboração das atividades deveria ter sido mais criteriosa; todos os detalhes deveriam ser plenamente checados (como clima, condições de acesso etc.) para não prejudicar a motivação;

b)na segunda excursão programada, os alunos já possuíam conceitos básicos de Geologia Estrutural; a atividade de campo teve caráter eminentemente treinadora no início, e investigativa no final, atingindo os níveis cognitivos de análise, síntese e avaliação (Bloom et al. 1973) do trabalho realizado. Houve participação equilibrada dos alunos com o professor, que considerou o resultado final mais positivo. Concluiu-se que, neste caso, foi vantajoso o fato de os alunos disporem de algum conteúdo teórico básico para a realização de atividades de campo.

Os alunos de cursos de graduação em Geologia passam o tempo todo "aprendendo sobre ciência", para finalizarem com a obrigação de "fazer ciência". Esse salto oferece dificuldades de toda sorte, pois envolve derradeiras atividades de campo investigativas. Para melhorar os resultados dessas atividades institucionais de campo, é geralmente útil o aprendizado de aspectos teóricos introdutórios, principalmente os postulados de metodologia científica.

AS ESCALAS DE OBSERVACÃO O primeiro contato dos alunos com mapas geológicos teve início pela leitura do texto "A natureza semiótica do mapa geológico" (Paschoale 1984b). Buscou-se valorizar e interpretar, individualmente, o problema da representação geológica. $\mathrm{O}$ tema central foi "O percurso técnico na impressão de mapas geológicos!', com a finalidade de obter subsídios teóricos, fundamentalmente históricos, para posterior trabalho em grupo. Algumas discussões abordaram a participacão da tecnologia e das empresas no desenvolvimento de mapas, favorecendo sua evolução pois, em determinado momento, houve necessidade da utilização de cores nos mapas impressos.

A abordagem da visão espacial envolveu, a seguir, a utilização de recursos cartográficos e diferentes escalas de representação, desde a Terra como um todo até atingir a escala de lâmina petrográfica. No exemplo específico, foi escolhida uma área-piloto a sudoeste do Estado do Rio de Janeiro - Figs. 1 e 2 - entre os municípios de Itaguaí e Pinheiral. Trabalhando-se com escalas e modelos foi construído um roteiro de trabalho, progressivamente reavaliado e condicionado às novas observações, ao longo da execução. $\mathrm{O}$ resultado da aplicação gerou novas questôes que automaticamente beneficiaram os estudos por parte dos alunos.

As escalas utilizadas partiram da análise de imagens de satélite e radar da área; escala $1: 2.500 .000$ - mapa geológico da América do Sul; escala 1:1.000.000 - mapa Geológico do Brasil; escala 1:250.000 folhas Volta Redonda e Rio de Janeiro; escala $1: 50.000$ - folhas Itaguaí e Piraí, RJ; escala $1: 25.000$ folha Volta Redonda NE; 1:1.000 planta topográfica da Estação Fitossanitária de Pinheiral; escalas mesoscópica (afloramento e amostra de mão) e posteriormente, lâmina delgada. As escalas poderiam ser regionalmente associadas ou adaptadas conforme o local de aplicação, escolhendo-se preferencialmente 0 ambiente geológico familiar aos alunos (neste caso o Rio de Janeiro).

$\mathrm{Na}$ atividade de campo programada os alunos analisaram as relações entre as diferentes escalas de observação; lançaram em mapa topográfico as estruturas observadas em campo e localizaram em rnapa as diferentes estruturas tectônicas associadas ao relevo existente na área. Os traços tectônicos observados no perfil foram basicamente as lineações, dobras, zonas de cisalhamento, contatos de intrusões graníticas, ou lentes de rochas ultramáficas e cálcio-silicáticas e marcadores cinemáticos. A observação de estruturas lineares, planares e dobradas no campo envolveu a realização de um perfil de $16 \mathrm{~km}$ (Fig. 2), com detalhamento de 6 (seis) afloramentos ao longo dos contatos geológi- 
Principais perfis de campo, parte leste da área estudada

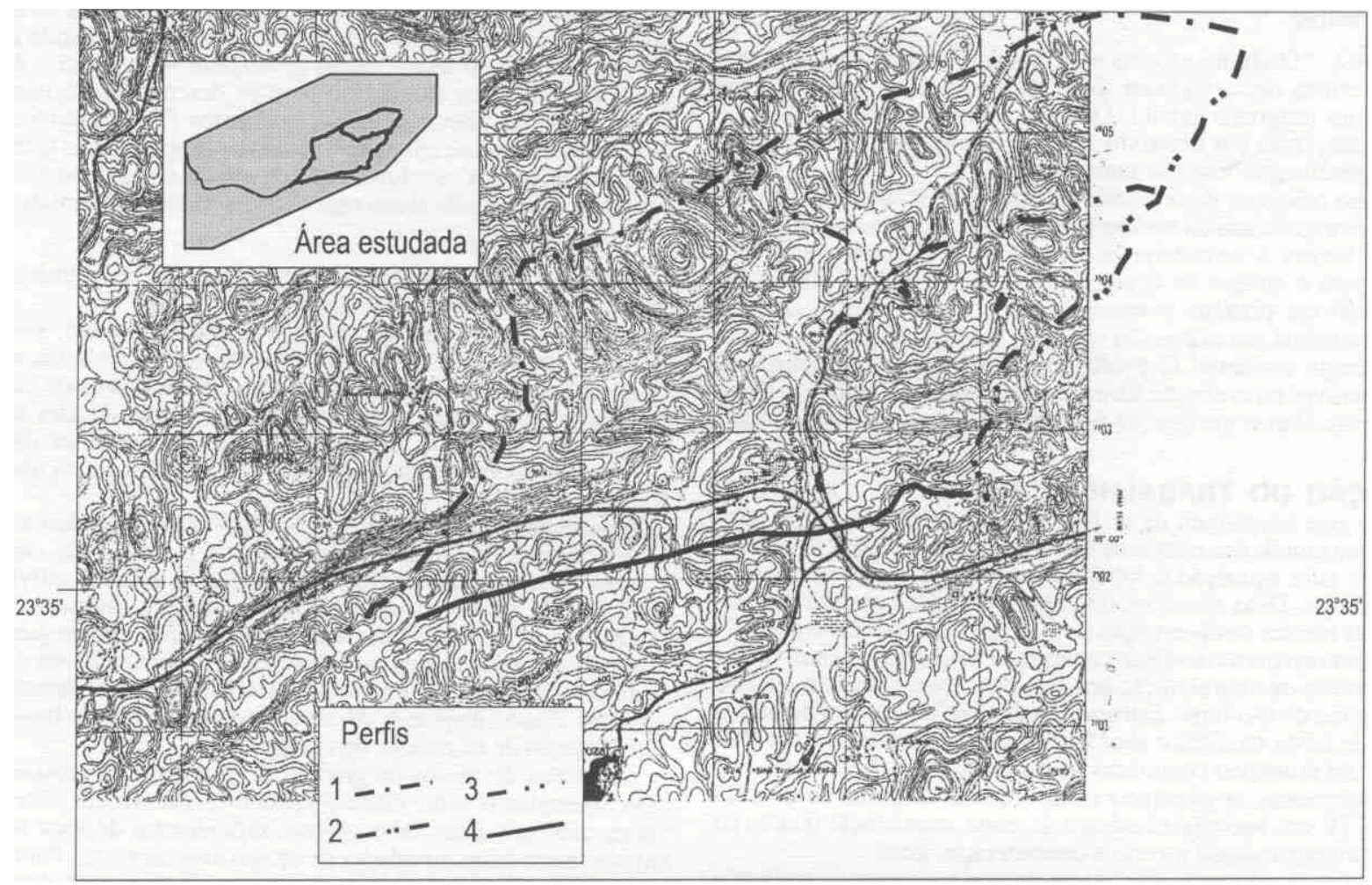

Figura 2 - Distribuição de alguns caminhamentos na parte leste da área estudada

cos transicionais de três unidades de mapeamento geológico muito semelhantes em campo: biotita gnaisse (BT), granada-biotitamoscovita xisto (GBMX) e gnaisse bandado grosso associado a granitos sin-orogênicos (GRÂ).

$\mathrm{Na}$ excursão principal realizada com os alunos, estes foram conduzidos nos afloramentos como prática normal, uma vez que o docente já havia cartografado a maioria dos afloramentos, sem no entanto ter realizando o roteiro integral. À medida que foi evoluindo o trabalho no campo, o docente sentiu, com surpresa, que existia uma estrutura de grande porte. Nesse perfil pode-se analisar ainda o aumento do grau metamórfico em direção à base da sequência, a partir da metade do perfil, definindo-se uma inversão tectono-metamórfico-estratigráfica em uma parte da seção. A atividade não foi do tipo indutiva, pois o docente realmente não sabia de antemão da existência da grande dobra, ou seja, os alunos seriam estimulados a definir uma megadobra no próprio campo. Adicionalmente, é preciso registrar que os alunos de final de curso de uma turma anterior haviam mapeado a área e não conseguiram enxergar tal feição. Logo que o docente sentiu que se tratava de uma ampla inflexão regional de estruturas, sua postura modificou-se, pois tratava-se de algo inteiramente novo.

$\mathrm{Na}$ etapa final, houve apresentação de diapositivos de afloramentos da região, abordando fundamentalmente os traços tectônicos, vinculados (neste caso) às amostras de mão coletadas. Posteriormente, os alunos procuraram localizá-los nos mapas em diferentes escalas. A análise microscópica de lâminas delgadas de amostras da região estudada (Fig. 3) finalizou todo o processo.

ANÁLISE E AVALIAÇÃO DOS RESULTADOS OBTIDOS O trabalho realizado buscou modificar principalmente a relação teoriapratica utilizada na disciplina Geologia Estrutural. Para tanto, foram programadas atividades com inversão dos aspectos teórico-práticos, ou seja, a proposta fundamental de trabalho era inverter a ordem dos elementos, colocando-se a prática antes da teoria. Outro aspecto visava fundamentalmente MOTIVAR os alunos da disciplina para as atividades de campo.

Buscou-se realizar a análise dos traços tectônicos existentes em amostras de mão sem fornecimento prévio de nomenclatura, ou seja, relacionando-se elementos e aspectos obtidos a partir de observações individuais. Neste tópico deve-se frisar que os elementos de estudo como dobras, foliações e lineações não tinham sido ainda estudados anteriormente, em qualquer outra disciplina.

$\mathrm{O}$ resultado desta atividade foi surpreendente, pois notou-se que os alunos, de maneira geral, já conheciam termos como: foliação, banda- mento composicional, dobras e lineações, mas não os relacionavam diretamente às feições que observavam. Foram igualmente realizados trabalhos de reconhecimento de estruturas tectônicas em atividade de campo.

Os alunos obtiveram maior interesse por estereogramas, ou seja, iniciaram sua preocupação com aspectos interpretativos dos estereogramas, pois os livros tratam, predominantemente, dos aspectos metodológicos de confecção. Igualmente, alcançaram a conclusão, individual, de que, quanto maior a escala, maior o detalhamento necessário na observação de estruturas no campo.

Quando se iniciou a atividade de campo, abordando estruturas tectônicas e suas relações com as escalas de observação, sem o conhecimento teórico prévio dos alunos, constatou-se ser extremamente difícil, para alguns deles, trabalhar temas complexos. A falta de embasamento teórico prévio os deixara inseguros quanto ao entendimento e consequente posição espacial das estruturas. O raciocínio lógico dos alunos apresentava-se fragmentado, ou seja, sua maior dificuldade era relacionar os dados de campo dos vários afloramentos visitados e entendê-los no âmbito de uma estrutura maior.

Em determinado momento do percurso de campo, surgiram problemas quanto ao processo mais adequado de localização em campo. $\mathrm{O}$ professor não participou nem induziu a discussão sobre o correto lançamento dos dados de campo no mapa topográfico. Houve, naquele momento, total incerteza quanto aos critérios que deveriam ser adotados. Foram pouco considerados os princípios de orientação por meio da geomorfologia, acidentes geográficos e rios, por mero desconhecimento (os alunos valorizaram principalmente estradas e construções); o professor precisou interferir na condução do debate. Houve ainda uma discussão sobre a grande importância dada à indicação correia de afloramentos em mapa geológico/fisiográfico que, sem sombra de dúvida, deu credibilidade e valorizou os trabalhos de campo.

Percorrendo um trecho que possuía indicadores cinemáticos da presença de zona de charneira de provável macroestrutura, as observações e comentários dos alunos definiram os principais parâmetros usualmente utilizados na análise em zona de charneira, ou seja, constataram aumento na frequência de lineações minerais (principalmente em moscovita) e dobras parasíticas de pequeno porte em forma de M. Apesar de insistirem em relacionar aquelas pequenas estruturas com outras maiores, os alunos não conseguiam sintetizar ou aplicar as informações de campo.

$\mathrm{Na}$ observação de afloramentos em análise estrutural de campo, o aluno deve observar atentamente os traços tectônicos e correlaciona- 


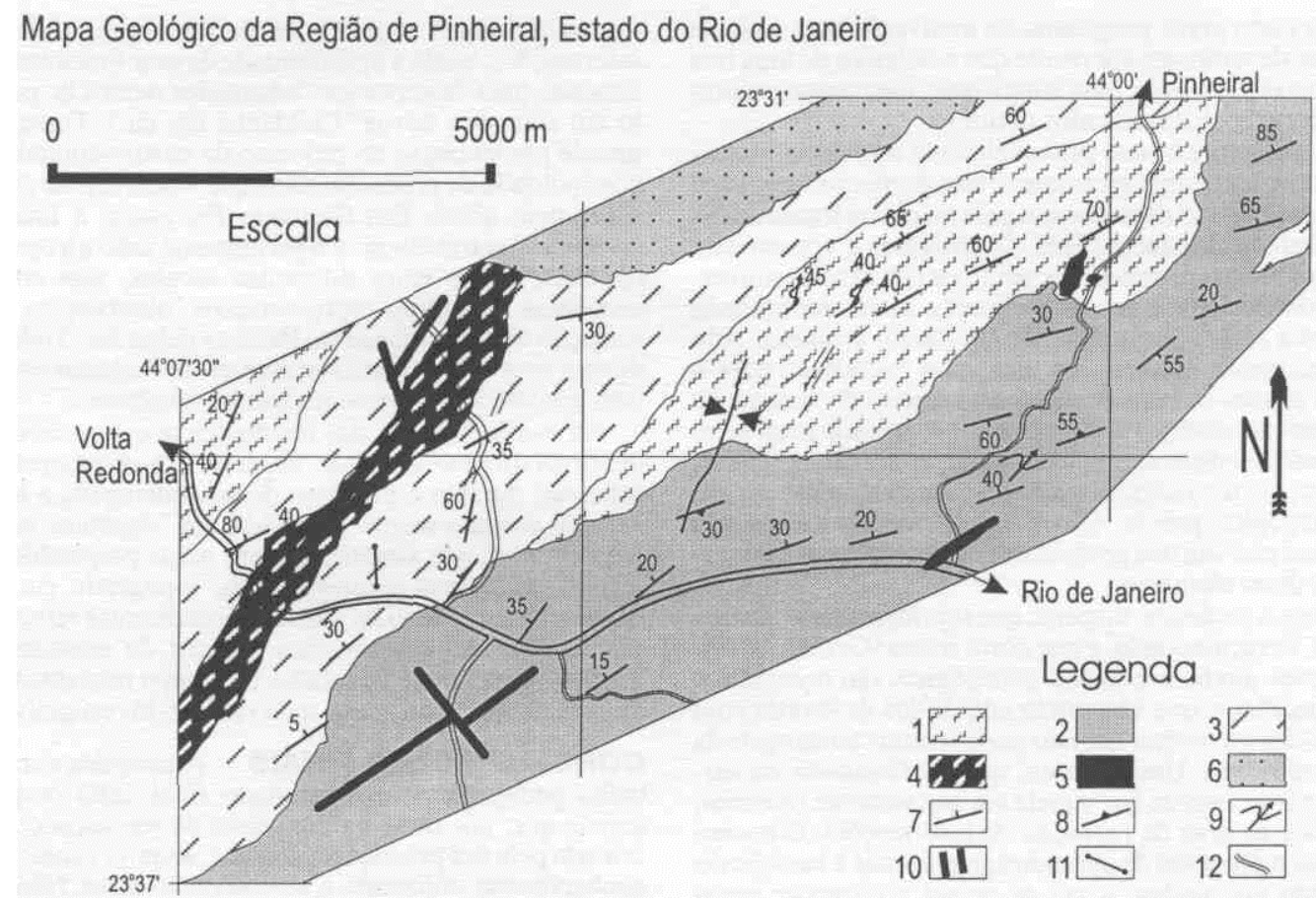

Figura 3 - Mapa geológico da região de Pinheiral, Estado do Rio de Janeiro. Convenções: 1. Biotita-moscovita gnaisse; 2, Microclina gnaisse porfiroclástico; 3. Biotita gnaisse; 4. Hornblenda-biotita gnaisse; 5. Rochas ígneas ácidas e básicas; 6. Sedimentos terciários da bacia de Volta Redonda; 7. Foliação gnáissica; 8. Foliação milonítica-C; 9. Dobras parasíticas "z" ou "s"; W. Falhas; 11 . Diques básicos cretáceos; 12. Estradas

los com estruturas maiores ou mais complexas. Tais procedimentos foram executados pêlos alunos, curiosamente, sem haver qualquer sugestão ou informação teórica prévia. Eles realmente sentiram necessidade de questionar, relacionar e concluir alguma coisa sobre os traços observados. À medida que foi sendo desenvolvido o trabalho, os procedimentos ficavam cada vez mais aprimorados, chegando até o nível de super-detalhe.

As semelhanças e diferenças entre os afloramentos foram, nesse ponto, levemente induzidas pelo professor, que tentou não participar ativamente da evolução dos debates sobre o raciocínio "geo"-lógico desenvolvido pelos alunos. Alguns mostraram dificuldade de entender a posição espacial de amostras coletadas. Uma observação interessante diz respeito à movimentação de suas mãos "no ar". Esse procedimento foi sistematicamente utilizado pelos alunos, provavelmente porque o professor sempre empregava esse artifício para se fazer entender. $\mathrm{O}$ professor considera a mão um instrumento útil para dispor o pensamento espacial, pois ela pode ser modificada espacialmente e interpretada como um plano, auxiliando efetivamente no entendimento das relações espaciais.

Saliente-se que, no percurso de campo, configurava-se uma macroestrutura dobrada (antiforma com caimento, em escala de mapa) de total desconhecimento dos alunos. Os alunos foram capazes de mapear no campo a dobra sem possuírem conceitos teóricos prévios.

No dia seguinte, durante a realização de trabalhos de gabinete, uma grande folha de cartolina branca foi colocada em cima da mesa, para observação pelos alunos. Com canetas coloridas representou-se graficamente a caminhada "geológica", com a locação dos afloramentos visitados. Cada aluno descreveu e discutiu com os demais as suas observações, tentando sempre relacionar as modificações dos diferentes dados de campo. No final, sintetizaram as suas informações. Quando finalizaram a representação gráfica, questionou-se o resultado. O que foi realizado? Neste momento, houve uma grande satisfação, até mesmo alegria por parte de alguns alunos, quando descobriram que eles haviam mapeado uma dobra e não sabiam o que era!

Como resultado final do trabalho, os alunos conseguiram chegar, sozinhos, às questões mais importantes dos trabalhos de campo (localização, locação correta de afloramentos, relações entre afloramentos e entendimento da sistemática de mapeamento, entre outros) demonstrando que a relação teoria-prática deve ser indissociável e que, se executarmos as atividades práticas antes da teoria, ou seja, se colocarmos os estudantes diante de problemas reais, poderemos obter sucesso mais efetivo no trabalho pedagógico.
Os alunos salientaram ainda os aspectos positivos e concordaram que melhorara substancialmente o aproveitamento e desempenho. Considera-se esta a grande vitória do trabalho. Constatou-se que o rendimento dos alunos, comparado aos anos anteriores, fora superior.

A segunda avaliação para finalizar o trabalho do semestre foi considerada não-formal e participativa, pois avaliou o conteúdo programático adquirido até aquele momento, a partir de sugestão feita pelos próprios alunos. Naquele momento foram esquecidos os aspectos tecnicistas e o professor optou por fazer uma avaliação participativa. Os alunos que optaram pelo método de avaliação escolheram "Seminário com Apresentação Oral" para compor a nota final. Pela primeira vez foi realizada uma avaliação diferente de prova escrita. $\mathrm{O}$ resultado obtido foi muito superior à avaliação formal, pois os alunos, neste aspecto, se desdobraram e atingiram o nível de análise de conteúdo com maior facilidade.

Houve, igualmente, participação na avaliação dos alunos, pois o docente colocou aspectos da avaliação individual e levantou questões para melhor aproveitamento das habilidades específicas dos alunos. Os alunos participaram do processo de avaliação dos seminários colocando os aspectos individuais e autocríticas de desempenho, tanto na parte escrita como no momento da apresentação oral. Houve debate dos aspectos abordados na parte teórica da matéria e no julgamento. $\mathrm{O}$ resultado final foi modesto mas gerou um grau de consciência das dificuldades em expor pensamentos e questões.

DISCUSSÃO A atividade de pesquisa deve ser encarada como dimensão fundamental dentro da proposta educativa, que visa tornar o aluno um sujeito crítico; tal postura torna-se evidente em um trabalho metodologicamente correio. Esta questão deve ser encarada como a verdadeira resposta da classe universitária à sociedade. $\mathrm{O}$ trabalho de pesquisa deverá ter função de fomentar o ensino baseado em despertar o interesse público pela ciência; elevar o nível didático das escolas; despertar vocações e orientá-las; criar entre os jovens o espírito associativo em torno da ciência; estimular o amadorismo científico, onde ele tenha cabimento. Este amadorismo pode constituir apreciável reserva de forças de trabalho científico de uma nação (Reis 1964).

Os alunos formados em escolas públicas federais (no exemplo) devem possuir, necessariamente, conceitos bem claros quanto à sua efetiva participação no momento político-social em que o Brasil se encontra, buscando fortalecer e divulgar os aspectos democráticos disseminados no âmbito acadêmico.

Outra função do professor é ser o elemento motivador para o aluno que, face aos problemas atuais em que se encontram as Universidades Públicas, necessitam de novos procedimentos estratégicos. Deve-se 
procurar executar a curto prazo programas de motivação para a classe estudantil. Portanto, devemos ter em mente que o objetivo de uma boa aula é motivar o aluno a pesquisar, para atingir questionamento próprio e consequente elaboração dos resultados obtidos.

Uma boa parte dos professores, provavelmente a maioria, baseia sua prática em prescrições pedagógicas que se transformaram em senso comum, incorporadas quando da passagem pela escola ou transmitidas por colegas mais velhos (Libâneo 1985). O professor é selecionado dentro do meio académico em concursos públicos (no caso de universidades públicas) dando ênfase ao conhecimento mais aprofundado sobre as disciplinas a serem ensinadas. São, portanto, avaliados pelo seu grau de conhecimento específico e não pelas "aptidões" para o ensino. Não são avaliados os conhecimentos a respeito do sistema de ensino-aprendizagem necessários à atuação e sucesso como professor. Neste aspecto o professor deve ser capaz de atuar, com maior eficácia, em benefício ao sucesso do aluno, baseado fundamentalmente em seu conhecimento pedagógico prévio. Quando colocamos esta questão deve ficar claro que a maioria dos professores contratados nas Universidades não dispõe deste elemento.

É fundamental que o professor suspeite, que seja insubmisso, crítico com o seu trabalho, desacomodado, e que corra riscos (Geraldi 1978). Portanto, para efetivar um bom trabalho pedagógico, são necessários conhecimentos específicos, que vão sendo adquiridos de acordo com seus anseios. Aprendemos melhor quando participamos ativamenteda descoberta de coisas novas. Uma aula em que participamos da discussão é muito mais interessante que aquela em que somente ouvimos, na qual limitamo-nos ao grau da recepção de informações. O ensino na sala de aula reduz o processo de aprendizagem apenas à audição do aluno. Uma aula em que podemos ver as coisas e observar como funcionam é mais empolgante que uma aula em que somente falamos sobre coisas. Finalmente, uma aula em que não somente falamos e vemos, mas também fazemos e descobrimos as coisas é fantástica! O que aprendemos por meio de nossas experiências e descobertas não esquecemos jamais. Tudo o que aprendemos por meio da (re)descoberta é permanente.

Um programa de ensino eficiente deverá fornecer aos alunos os princípios básicos de aprendizado (Werner 1982):

1.Observação: incentivar o aluno a olhar as coisas de perto, sem receio, e a fazer perguntas pertinentes.

2.Compreensão: ajudar o aluno a analisar os problemas com

espírito crítico, trabalhando juntos para encontrar soluções.

5. Ação: alunos e professores aprendem juntos por meio da ex-

periência e da prática.

Outro aspecto importante diz respeito à estrutura da disciplina. Para facilitar o processo de aquisição do conhecimento, costuma-se tradicionalmente dividir a matéria de ensino em disciplinas. $\mathrm{O}$ vocábulo disciplina está ligado, originalmente, à ideia de disciplina mental: desenvolver e manter um determinado tipo de organização no plano de ideias, por meio do assunto que é estudado. Entretanto, se a divisão da matéria de ensino em disciplinas visa evitar o contato do aluno, de uma só vez, com uma massa compacta de informações, por outro lado é preciso cuidado no sentido de que as disciplinas não sejam desenvolvidas de forma isolada umas das outras. Pode haver quebra ou fragmentação da continuidade dos assuntos propostos para estudo e na propria organização lógica, dificultando ao aluno a integração de conhecimentos (Saldanha 1974).

Segundo Saldanha (1974) a matéria a ser ensinada envolve, basicamente, um "conjunto estruturado de conhecimentos científicos" dispostos com o objetivo de permitir que o aluno adquira novas informações, tendo a oportunidade de usar funcionalmente esse conhecimento, para desenvolver "adequados modos de pensá-lo e de aplicálo em situações novas" (Saldanha op. cit.). Torna-se claro que uma grande preocupação do processo de ensino-aprendizagem refere-se à continuidade de procedimentos que visem a uma efetiva aquisição do saber pelo aluno. Em Geologia Estrutural a linha mestra - ou fio condutor dos trabalhos - é o permanente salto e a contínua transposição de observações entre diferentes escalas, seja em mapas, seja em esquemas, desenhos, representações, observações de campo e interpretação de fotos aéreas ou lâminas delgadas. Todos esses elementos devem estar disponíveis e acessíveis aos estudantes, para que se atinja uma qualidade de ensino realmente satisfatória.

$\mathrm{Na}$ avaliação final dos resultados que possibilitem a melhoria no desenvolvimento da visão espacial em diferentes escalas podemos salientar, durante o processo de aprendizagem, a inversão efetiva da relação prática-teoría associada aos seguintes aspectos: conceitos básicos amplos e sintetizados em aulas preparatórias (confecção de mapas geológicos e topográficos, topografia etc.); valorização do conhecimento prévio do aluno bem como suas relações com diferentes escalas; reforço em aspectos básicos de metodologia científica, e desenvolvimento de atividades de campo inicialmente expositivas-indutivas, finalizando como motivadoras-investigativas.

CONSIDERACÕES FINAIS A pesquisa como base para o trabalho pedagógico foi o resultado final desta proposta. Professor é aquele que, por meio da conquista de seu espaço académico, representado pela sua produção científica, adquire condições para transmitir conhecimento utilizando o ensino como meio. Não é professor quem na essência não é pesquisador. Pesquisador no sentido amplo da palavra, que mostra verdadeiro interesse na qualidade do produto final de ensino, que irá ultrapassar os limites da Universidade.

Para ser eficiente, a educação precisa ser prática, envolvendo os princípios básicos de aprendizado: observação, compreensão e ação. $O$ aluno deve observar, compreender e experimentar ou aplicar as formas de melhorar seu entendimento sobre os diferentes assuntos. Para efetivar o ensino-aprendizagem faz-se necessário dispor de um plano de ensino. Na elaboração do plano, o problema do professor é justamente buscar a melhor maneira de comunicar o saber ao aluno, criando oportunidades para que este possa selecionar e associar ideias, organizar seus próprios esquemas mentais e desenvolver habilidades, a partir de um corpo de conhecimentos prévia e criteriosamente selecionado e organizado pelo professor.

Conteúdo da matéria de ensino e processo de aprendizagem estão intimamente relacionados. Diante disto, o professor deve selecionar o que é realmente relevante e conciliá-lo com a necessidade de que o aluno (futuro profissional) possa atingir níveis mais altọ de reflexão, indagação autónoma e aplicação adequada de conhecimentos. Contudo, ao proceder à seleção de conteúdos para o plano de ensino, o professor também levará em consideração outros elementos, tais como:

Os objetivos que se pretende alcançar, analisando os pré-requisitos e resultados esperados;

As condições previstas para o aluno atingir os objetivos propostos; O critério de avaliação que será utilizado;

Distribuição de tempo face ao número de alunos, considerando que, em pequenas turmas (no exemplo descrito), este aspecto é mais bem superado.

\section{Referências}

Anguila Virella F. \& Ancochea Soto E. 1981. Prácticas de campo: alternativas a Ia cxcursión tradicional. In: SIMPOSIO SOBRE ENSEÑANZA DE LA GEOLOGIA, 1, Madrid. Anates... Madrid, p. 317-326.

Bloom B.S. et al. Taxionomia de objetivos educacionais. Domínio Cognitivo. Porto Alegre: Editora Globo. 1973

Brítannica. Enciclopedia Britannica do Brasil. 1985. O Grand Canyon: resumo da geologia. São Paulo. (Fita de vídeo VHS, 24', BV-049).

Compiani M. \& CarneiroC.D.R. 1993. Os papéis didáticos das excursões geológicas. Rev. de Ia Enseñanza de Ias Ciências de Ia Tierra, 1(2):90-98.

Fischer R.M.B. 1976. A questão das técnicas didáticas: uma proposta comprometida $\mathrm{cm}$ lugar da decantada neutralidade das técnicas didático-pedagógicas. Ijuí, novembro, (mimeo)

Gadotti M. 1988. O pensamento pedagógico brasileiro. 2 ed. SSo Paulo: Ática. 160 p.

Libâneo J.C. 1985. Democratização da Escola Pública. A pedagogia crítico-social dos conteúdos. São Paulo: Loyola. 149 p.

Moreira A.F.B. 1994. Escola, Currículo e a Construção do Conhecimento. In: Escola Básica. 2 ed. Campinas: Papirus. p. 77-88. (Coletânea CBE) p. 77-88

Nummer A.R. \& Carneiro C.D.R. 1998. The comprehension of space by lhe study of tectonic structures on differcnt observation scales. In: International Confercncc on Gcosdencc Education, 2, Hilo, Hawaii, 1997. Conference Proceedings... Ohio: The Ohio State University. p. 160
Paschoalc C. 1984. Semiótica de mapas geológicos e geotécnicos. São Paulo: Pós-Grad. PUC-SP. 21 p. (mimcogr.- monogr.aprcs.disc. Núcleo de Pesquisa)

Reis J.A. 1964. A Divulgação Científica e o Ensino. Ciência e Cultura. 16(4):352-353,

Saldanha L. (Coord.). 1974. Seleção do conteúdo da matéria de ensino. In: Planejamento e organização do ensino. Porto Alegre: Globo.

Santanna F. et al. 1988. Dois enfoques modernos sobre planejamento: o sistémico e o participativo. In: Planejamento de ensino e avaliação. $11 \mathrm{ed}$. Porto Alegre: Sagra.

Saviani D. 1991. Escola e Democracia. São Paulo: Cortez. p. 15-40.

Silva T.T. da, 1992. O que produz e o que reproduz em Educação. Ensaios de Sociologia da Educação. Porto Alegre: Artes Médicas, 1992.p. 60

Sociedade Brasileira de Geologia. 1981. Teses. In: Simpósio Nacional sobre o Ensino da Geologia no Brasil, 1, 2. São Paulo: SBG. (Teses, vol. I e II).

Manuscrito A-1024

Recebido em 02 de setembro de 1998 Revisão dos autores em 05 de dezembro de 1999 Revisão aceita em 10 de dezembro de 1999 